\title{
Fosfatos com diferentes relações flúor:fósforo na alimentação de frangos de corte
}

\author{
Elenice Maria Casartelli ${ }^{1}$, Otto Mack Junqueira ${ }^{1}$, Lúcio Francelino Araújo ${ }^{2}$, Cristiane Soares \\ da Silva Araújo ${ }^{1}$, Davi Savietto ${ }^{2}$, Messias Alves da Trindade Neto ${ }^{3}$
}

\footnotetext{
${ }^{1}$ Faculdade de Ciências Agrárias e Veterinárias - FCAVJ/UNESP, CEP: 148894-900 - Jaboticabal/SP - Brasil.

2 Faculdade de Zootecnia e Engenharia de Alimentos - FZEA/USP, CEP: 13635-900 - Pirassununga/SP - Brasil.

${ }^{3}$ Faculdade de Medicina Veterinária e Zootecnia - FMVZ/USP, CEP: 13635-900 - Pirassununga/SP - Brasil.
}

RESUMO - Um experimento foi conduzido com o objetivo de verificar os efeitos de diferentes relações flúor:fosforo na alimentação sobre o desempenho de frangos de corte. Foram utilizados 1.000 pintos de corte de 1 dia distribuídos em um delineamento inteiramente casualizado, com quatro tratamentos e cinco repetições de 50 aves por boxe. Os tratamentos consistiram de quatro fontes de fósforo com relações flúor:fósforo de 1:40, 1:60, 1:80 e 1:100. O experimento foi dividido em três fases experimentais: 1 a 21, 22 a 42 e 43 a 49 dias de idade. Em cada fase, avaliou-se o consumo de ração, o ganho de peso e a conversão alimentar. Ao final do experimento, foram abatidas duas aves de cada repetição para coleta da tíbia e de músculos do peito para análise das concentrações de flúor, cálcio, fósforo e magnésio desses tecidos. As relações flúor:fósforo avaliadas não afetaram o desempenho dos frangos de corte. A deposição óssea de flúor é proporcional à sua concentração na dieta, no entanto, a elevação dos níveis de flúor da dieta não influencia sua deposição nos músculos.

Palavras-chave: desempenho, fontes de fósforo, minerais

\section{Phosphates with different fluorine:phosphorus relations in the diet for broiler chicken}

\begin{abstract}
An experiment was conducted to evaluate the effect of different fluorine:phosphorus ratios in the diet on performance of broiler chickens. One thousand broiler chickens with one day old were allotted to a completely randomized experimental design with four treatments with five replications of fifty broilers per experimental unit. The treatments was composed by four phosphorus sources with fluorine: phosphorus ratios of 1:40, 1:60,1:80, 1:100 and fed during three experimental phases: 1-21, 22-42 and 43-49 days. In each phase, feed intake, weight gain and feed conversion were evaluated. At the end of experiment, two birds per replication were slaughtered and their tibias and samples of muscle tissue from breast were collected for determination of fluorine, calcium, phosphorus and magnesium contents. The fluorine to phosphorus ratios did not affect the performance of broiler chickens. Bone deposition of fluorine is proportional to their concentration in diet. However, the increase of fluorine levels in diet does not influence their deposition in the muscle tissue.
\end{abstract}

Key Words: minerals, performance, phosphorus sources

\section{Introdução}

O uso dos fosfatos de rocha como fonte de cálcio e fósforo em dietas para animais domésticos visa à redução da quantidade de produtos importados, como o fosfato bicálcico, e à diminuição do custo de produção das rações. Contudo, seu uso pode ser prejudicial às características ósseas, uma vez que não há padronização dos seus conteúdos de fósforo, cálcio e flúor e da disponibilidade biológica desses minerais (Junqueira, 1991; Guinotte et al., 1991).
De acordo com Gomes (1991), a maior restrição ao uso de fosfatos naturais na alimentação de animais domésticos é seu elevado teor de flúor, embora a forma predominantemente encontrada nesses fosfatos seja o fluoreto de cálcio, menos absorvível. Segundo Gomes et al. (1989), a análise da toxidez do flúor nos ossos é necessária para avaliar o prejuízo provocado nos animais adultos e em crescimento. Nos animais em crescimento, o flúor interfere na mineralização óssea por formar complexo com o cálcio e o fósforo, que os tornam indisponíveis para absorção e utilização no metabolismo orgânico. 
O flúor não apresenta a mesma toxicidade em todas as espécies. As aves são a espécie com maior tolerância, seguidas pelos suínos, eqüinos, ovinos e bovinos. De modo geral, os animais jovens são mais sensíveis (NRC, 1974). Resultados de um estudo conduzido por Gerry (1949) sugerem que níveis de flúor de 300 a $400 \mathrm{mg} / \mathrm{kg}$ para aves em crescimento e de 500 a $700 \mathrm{mg} / \mathrm{kg}$ para poedeiras são seguros quando se utilizam esses tipos de suplementação mineral.

Gardiner (1961) e Spierto (1969) não notaram efeitos do flúor sobre a porcentagem de fósforo e cálcio nos ossos de aves em início de crescimento alimentadas com dietas com altos teores de flúor. Com uso de níveis adequados de flúor, como os utilizados por Merkley (1976), notou-se que a adição de flúor na água de beber aumentou a resistência à fratura do úmero e da tíbia. Assim, aumento na concentração de flúor nos ossos pode ocorrer sem sinais de intoxicação.

Considerando esses aspectos, realizou-se este trabalho com o objetivo de analisar o uso de fosfatos com diferentes relações flúor:fósforo na alimentação de frangos de corte.

\section{Material e Métodos}

Foram utilizados 1.000 pintos de 1 dia de idade de uma linhagem comercial. Ao início do experimento, as aves foram pesadas, selecionadas e distribuídas em um delineamento inteiramente casualizado. Os frangos foram mantidos em boxes de $3,15 \times 1,50 \mathrm{~m}$, em um galpão convencional de alvenaria com $30 \times 6,65 \mathrm{~m}$, cumeeira com orientação nortesul, pé-direito de $2,5 \mathrm{~m}$, sem lanternim, coberto com telhas de fibrocimento, contendo mureta de alvenaria de $0,40 \mathrm{~m}$ e tela de arame, protegido por cortina de plástico amarela com sistema móvel de catraca para movimentação no controle do ambiente interno. As aves receberam água e alimentação à vontade.

Os boxes possuíam cama de maravalha e foram equipados durante as fases iniciais com lâmpada infravermelha para aquecimento dos pintinhos, comedouros tipo tubular infantil e bebedouros de pressão. A substituição dos equipamentos infantis ocorreu a partir do quinto dia de idade. No terceiro dia, iniciou-se a introdução, concomitante, dos equipamentos para aves adultas. $O$ controle do aquecimento e o manejo das cortinas foram realizados de acordo com a necessidade das aves. O programa de luz adotado foi o de 24 horas de iluminação em todas as fases de criação. As aves foram vacinadas no décimo dia de idade contra newcastle e gumboro, via água de bebida.

No início do período experimental, os pintinhos foram distribuídos ao acaso em um delineamento inteiramente casualizado com quatro tratamentos e cinco repetições de 50 aves. Avaliaram-se quatro relações flúor:fósforo (1:40, 1:60, 1:80 e 1:100) obtidas pela inclusão de fosfatos nas rações (Tabela 1 ).

Tabela 1 - Composição química dos fosfatos

\begin{tabular}{lcccc}
\hline & \multicolumn{4}{c}{ Relação flúor:fósforo } \\
\cline { 2 - 5 } & $1: 40$ & $1: 60$ & $1: 80$ & $1: 100$ \\
\hline P (\%) & 19,95 & 19,80 & 19,85 & 19,90 \\
Solubilidade em citrato (\%) & 98,00 & 96,40 & 93,80 & 90,00 \\
Solubilidade em água (\%) & 18,21 & 40,81 & 28,35 & 9,80 \\
Flúor (\%) & 0,50 & 0,33 & 0,25 & 0,19 \\
Fósforo:flúor & 40,00 & 60,00 & 80,00 & 100,00 \\
Ca (\%) & 18,00 & 20,44 & 20,17 & 22,80 \\
Acidez (\%) & 5,18 & 1,10 & 0,95 & 0,06 \\
Umidade (\%) & 6,38 & 8,00 & 6,08 & 1,33 \\
\hline
\end{tabular}

Tabela 2 - Composição das dietas experimentais

\begin{tabular}{|c|c|c|c|c|c|c|c|c|c|c|c|c|}
\hline & \multicolumn{4}{|c|}{ Fase inicial } & \multicolumn{4}{|c|}{ Fase de crescimento } & \multicolumn{4}{|c|}{ Fase final } \\
\hline Milho & 53,27 & 53,49 & 53,45 & 53,65 & 58,10 & 58,29 & 58,39 & 58,45 & 62,85 & 63,03 & 62,97 & 62,76 \\
\hline Óleo & 4,42 & 4,35 & 4,36 & 4,29 & 5,10 & 5,04 & 5,05 & 4,98 & 5,92 & 5,86 & 5,88 & 5,95 \\
\hline Fosfato & 1,55 & 1,55 & 1,58 & 1,60 & 1,41 & 1,41 & 1,44 & 1,45 & 1,50 & 1,52 & 1,55 & 2,06 \\
\hline Calcário & 1,43 & 1,33 & 1,32 & 1,21 & 1,44 & 1,35 & 1,34 & 1,24 & 1,25 & 1,15 & 1,15 & 0,74 \\
\hline $\begin{array}{l}\text { Suplemento vitamínico } \\
\text { e mineral* }\end{array}$ & 0,50 & 0,50 & 0,50 & 0,50 & 0,50 & 0,50 & 0,50 & 0,50 & 0,50 & 0,50 & 0,50 & 0,50 \\
\hline Total & 100 & 100 & 100 & 100 & 100 & 100 & 100 & 100 & 100 & 100 & 100 & 100 \\
\hline
\end{tabular}

* Suplemento vitamínico-mineral/kg de ração - Fase inicial: vit. A - 1.500 UI; vit. $\mathrm{D}_{3}$ - 500 UI; vit. E - 20 mg; vit. K - 0,49 mg; vit. $B_{1}-2$ mg; vit. $B_{2}$ $6,6 \mathrm{mg}$; vit. $\mathrm{B}_{6}-2 \mathrm{mg}$; vit. $\mathrm{B}_{12}-20 \mathrm{mcg}$; niacina - $100 \mathrm{mg}$; ácido fólico - 0,5 mg; ăcido pantotênico - $10 \mathrm{mg}$; biotina - 0,02 mg; colina - $250 \mathrm{mg}$; Se $0,25 \mathrm{mg}$; antioxidante - 0,63 mg; Mn - $120 \mathrm{mg} ; \mathrm{Zn}-100 \mathrm{mg} ; \mathrm{Fe}-50 \mathrm{mg}$; Cu - $75 \mathrm{mg} ; \mathrm{I}-1,25 \mathrm{mg}$; coccidicida - $125 \mathrm{mg}$.

* Suplemento vitamínico-mineral/kg de dieta - Fase de crescimento: vit. A - 1.500 UI; vit. $\mathrm{D}_{3}-500 \mathrm{UI}$; vit. E - 2 mg; vit. K - 0,49 mg; vit. B - 2 mg; vit. $B_{2}-6,6 \mathrm{mg}$; vit. $\mathrm{B}_{6}-2 \mathrm{mg}$; vit. $\mathrm{B}_{12}-20 \mathrm{mcg}$; niacina - $100 \mathrm{mg}$; ácido fólico - 0,5 mg; ácido pantotênico - $10 \mathrm{mg}$; biotina - 0,02 mg; Se - 0,25 mg; antioxidante - 0,63 mg; Mn - $120 \mathrm{mg} ; \mathrm{Zn}-100 \mathrm{mg} ; \mathrm{Fe}-50 \mathrm{mg} ; \mathrm{Cu}-75 \mathrm{mg} ; \mathrm{I}-1,25 \mathrm{mg}$; coccidicida - $110 \mathrm{mg}$.

* Suplemento vitamínico-mineral/kg de ração - Fase final: vit. A - 1.500 UI; vit. $\mathrm{D}_{3}-250$ UI; vit. E - 1 mg; vit. K - 0,49 mg; vit. B 1 - 2 mg; vit. B 2

$1,75 \mathrm{mg}$; vit. $\mathrm{B}_{6}-2 \mathrm{mg}$; vit. $\mathrm{B}_{12}-5 \mathrm{mcg}$; niacina - $100 \mathrm{mg}$; ácido fólico - 0,25 mg; ácido pantotênico - $10 \mathrm{mg}$; biotina - 0,02 mg; Se - 0,25 mg; antioxidante -

$0,63 \mathrm{mg} ; \mathrm{Mn}-120 \mathrm{mg} ; \mathrm{Zn}-100 \mathrm{mg} ; \mathrm{Fe}-50 \mathrm{mg} ; \mathrm{Cu}-75 \mathrm{mg} ; \mathrm{I}-1,25 \mathrm{mg}$. 
As rações, isocalóricas e isoprotéicas, foram formuladas à base de milho e farelo de soja (Tabelas 2 e 3) como ingredientes energético e protéico, respectivamente, segundo exigências nutricionais preconizadas pelo NRC (1994).

A duração do experimento foi de 49 dias, subdivididos em três fases (1 a 21, 22 a 42 e 43 a 49 dias de idade). Em cada uma das fases, foram avaliados o ganho de peso, o consumo de ração e a conversão alimentar. Ao final do experimento, foram abatidos dois frangos por parcela, totalizando dez aves por tratamento para coleta de amostras de músculo do peito e da tíbia para determinação dos teores de cálcio, fósforo, magnésio e flúor nesses tecidos.

Parte das análises foi realizada no Laboratório de Nutrição da FCAVJ/UNESP, onde os ossos foram limpos, secos em estufa de ventilação forçada a $65^{\circ} \mathrm{C}$ por 72 horas, desengordurados com éter de petróleo em extrator de Soxhlet por 8 horas, fervidos com detergente neutro por 15 minutos e secos mais uma vez em estufa a $65^{\circ} \mathrm{C}$. As amostras secas e desengorduradas foram enviadas ao Laboratório da Fertilizantes Serrana S/A, em Cajati, SP, para análise dos teores de cálcio, fósforo e magnésio. As análises do teor de flúor foram realizadas no Laboratório do Instituto de Pesquisa Tecnológica da USP.

Os resultados obtidos foram analisados por meio do programa ESTAT, desenvolvido pelo departamento de Ciências Exatas, UNESP, em Jaboticabal, SP, e, em caso de diferença estatística, as médias foram comparadas pelo teste Tukey $(\mathrm{P}<0,05)$.

\section{Resultados e Discussão}

$\mathrm{Na}$ fase inicial (1 a 21 dias de idade), quando as aves receberam a dieta com relação 1:40 (flúor:fósforo), houve menor consumo de ração e melhor conversão alimentar $(\mathrm{P}<0,05)$, entretanto, quando alimentadas com a ração contendo relação 1:60, o consumo aumentou significativamente e a conversão alimentar piorou (Tabela 4). Nesse mesmo período, o ganho de peso não foi influenciado $(\mathrm{P}>0,05)$ por nenhuma das relações testadas. A redução do consumo quando fornecido o fosfato com relação 1:40 decorreu do maior conteúdo de flúor nesta fonte, uma vez que este elemento promove redução do consumo de ração. Esse resultado está de acordo com o descrito por Gardner et al. (1968), que, ao utilizarem dieta contendo elevado teor de flúor, verificaram redução do consumo.

Nos períodos de 22 a 42 dias e de 43 a 49 dias de idade, não houve efeito significativo das relações flúor:fósforo sobre nenhuma das variáveis estudadas. Entretanto, em termos numéricos, o consumo de ração pelas aves alimentadas com a dieta contendo relação 1:40 foi menor nos dois períodos avaliados. Analisando os dados referentes ao período total, entre o $1^{\text {o }}$ e $49^{\circ}$ dia de idade (Tabela 7), observou-se também que não houve diferença estatística entre as relações flúor:fósforo estudadas. Contudo, pela análise dos períodos, verificou-se tendência de menor consumo entre as aves que receberam maior concentração de F. Numericamente, estas aves apresentaram também melhor conversão alimentar, em decorrência do menor consumo.

Os resultados encontrados neste estudo comprovaram maior sensibilidade das aves durante a fase inicial, conforme citado por Rezende et al. (1999). À medida que essas aves vão alcançando a maturidade, os efeitos provocados pelo flúor diminuem. Resultados obtidos por Rama Rao \& Reddy (2001) corroboram parcialmente os achados deste estudo. Esses autores, ao analisarem diferentes fontes de fósforo e suas relações com seu conteúdo de flúor, concluíram que dietas formuladas com diferentes fontes de fósforo e concentração de flúor entre $365 \mathrm{mg} / \mathrm{kg}$ e $437 \mathrm{mg} / \mathrm{kg}$ não afetam o desempenho de frangos de corte.

Por outro lado, esses dados diferem do normalmente encontrado na literatura de que os fosfatos naturais podem não prejudicar o desempenho de frangos de corte. Veloso et al. (1996) constataram que os fosfatos naturais, mais ricos em flúor, foram piores para o ganho de peso. Esses autores comentaram ainda que este elemento provavelmente foi o

Tabela 3 - Composição nutricional das dietas experimentais

\begin{tabular}{|c|c|c|c|c|c|c|c|c|c|c|c|c|}
\hline & \multicolumn{4}{|c|}{ Fase inicial } & \multicolumn{4}{|c|}{ Fase de crescimento } & \multicolumn{4}{|c|}{ Fase final } \\
\hline & $1: 40$ & $1: 60$ & $1: 80$ & $1: 100$ & $1: 40$ & $1: 60$ & $1: 80$ & $1: 100$ & $1: 40$ & $1: 60$ & $1: 80$ & $1: 100$ \\
\hline $\begin{array}{l}\text { Energia metabolizável } \\
\text { (kcal/kg) }\end{array}$ & 3.100 & 3.100 & 3.100 & 3.100 & 3.200 & 3.200 & 3.200 & 3.200 & 3.300 & 3.300 & 3.300 & 3.300 \\
\hline Proteína bruta (\%) & 22,00 & 22,00 & 22,00 & 22,00 & 20,00 & 20,00 & 20,00 & 20,00 & 18,00 & 18,00 & 18,00 & 18,00 \\
\hline Lisina (\%) & 1,19 & 1,19 & 1,19 & 1,19 & 1,06 & 1,06 & 1,06 & 1,06 & 0,95 & 0,95 & 0,95 & 0,95 \\
\hline Metionina (\%) & 0,54 & 0,54 & 0,54 & 0,54 & 0,42 & 0,42 & 0,42 & 0,42 & 0,35 & 0,35 & 0,35 & 0,35 \\
\hline Metionina + cistina(\%) & 0,90 & 0,90 & 0,90 & 0,90 & 0,75 & 0,75 & 0,75 & 0,75 & 0,66 & 0,66 & 0,66 & 0,66 \\
\hline Fósforo disponível (\%) & 0,44 & 0,44 & 0,44 & 0,44 & 0,40 & 0,40 & 0,40 & 0,40 & 0,37 & 0,37 & 0,37 & 0,37 \\
\hline Cálcio (\%) & 0,97 & 0,97 & 0,97 & 0,97 & 0,93 & 0,93 & 0,93 & 0,93 & 0,87 & 0,87 & 0,87 & 0,87 \\
\hline Fósforo total (mg/kg) & 93 & 51 & 38 & 21 & 85 & 47 & 35 & 19 & 90 & 50 & 37 & 27 \\
\hline
\end{tabular}


Tabela 4 - Desempenho de frangos de corte alimentados com rações contendo fonte de fósforo com diferentes relações flúor:fósforo

\begin{tabular}{|c|c|c|c|c|c|}
\hline & \multicolumn{4}{|c|}{ Relação flúor:fósforo } & \multirow[t]{2}{*}{ CV (\%) } \\
\hline & $1: 40$ & $1: 60$ & $1: 80$ & $1: 100$ & \\
\hline \multicolumn{6}{|c|}{1 a 21 dias de idade } \\
\hline Consumo (g) & $968 b$ & $1.093 a$ & $1.029 a b$ & $1.017 \mathrm{ab}$ & 5,18 \\
\hline Ganho de peso (g) & $774 a$ & $772 \mathrm{a}$ & 789a & $764 a$ & 3,36 \\
\hline Conversão (g/g) & $1,25 b$ & $1,42 \mathrm{a}$ & $1,30 \mathrm{ab}$ & 1,33ab & 5,62 \\
\hline \multicolumn{6}{|c|}{22 a 42 dias de idade } \\
\hline Consumo (g) & $3.092 \mathrm{a}$ & $3.187 \mathrm{a}$ & $3.263 a$ & $3.152 \mathrm{a}$ & 6,08 \\
\hline Ganho de peso (g) & $1.676 \mathrm{a}$ & $1.703 \mathrm{a}$ & $1.751 \mathrm{a}$ & $1.697 \mathrm{a}$ & 4,46 \\
\hline Conversão (g/g) & $1,84 a$ & $1,87 a$ & $1,86 \mathrm{a}$ & $1,86 a$ & 6,09 \\
\hline \multicolumn{6}{|c|}{43 a 49 dias de idade } \\
\hline Consumo (g) & $1179 a$ & $1201 \mathrm{a}$ & $1285 a$ & $1175 a$ & 5,61 \\
\hline Ganho de peso (g) & $421 \mathrm{a}$ & $457 \mathrm{a}$ & $457 \mathrm{a}$ & $402 \mathrm{a}$ & 4,13 \\
\hline Conversão (g/g) & $2,80 \mathrm{a}$ & $2,63 a$ & $2,81 \mathrm{a}$ & $2,92 \mathrm{a}$ & 5,72 \\
\hline \multicolumn{6}{|c|}{ Período total (1 a 49 dias de idade) } \\
\hline Consumo (g) & $5.239 a$ & $5.481 \mathrm{a}$ & $5.570 \mathrm{a}$ & $5.343 \mathrm{a}$ & 4,81 \\
\hline Ganho de peso (g) & $2.872 \mathrm{a}$ & 2.933a & $2.998 a$ & $2.864 \mathrm{a}$ & 3,24 \\
\hline Conversão (g/g) & $1,82 \mathrm{a}$ & $1,87 \mathrm{a}$ & $1,86 a$ & $1,87 \mathrm{a}$ & 4,20 \\
\hline
\end{tabular}

Médias, seguidas de mesma letra, dentro de cada variável analisada, não diferem $(P>0.05)$ significativamente pelo teste Tukey.

fator que mais interferiu na utilização das fontes de fósforo, uma vez que foi utilizada a mesma ração básica e os níveis de fósforo foram equalizados em todos os tratamentos, portanto, as diferenças no ganho de peso podem estar relacionadas ao teor de flúor nas rações.

A tendência de os fosfatos naturais causarem menor peso corporal e menor consumo de ração permite supor que o menor ganho de peso decorreu do menor consumo de ração, que foi influenciado pela presença de níveis mais elevados de flúor nas rações com os fosfatos naturais, reduzindo a eficiência de utilização do alimento. Infere-se, por essas observações, que esses sinais são sintomas da toxidade de flúor, que reduz o consumo de alimento. (Karunajeewa, 1975; De Bruyne \& Von Felde, 2000).

Acredita-se que, além do flúor, podem existir nos fosfatos naturais outros fatores não identificados que afetariam adversamente as aves (Cavalheiro et al., 1986). Por outro lado, Lourenço et al. (1986) verificaram que aves alimentadas com fosfatos de rocha tiveram desempenho comparável ao daquelas que receberam fosfatos elaborados e recomendaram o uso dos fosfatos de rocha na alimentação.

Neste estudo, não houve diferença significativa entre as aves quanto à deposição óssea de cálcio e fósforo. A deposição de flúor apresentou diferença estatística e aumentou de acordo com a concentração de flúor da fonte utilizada. Esses resultados estão de acordo com os achados
Tabela 5 - Concentrações de minerais na tíbia e no músculo do peito de frangos de corte alimentados no período de 1 a 49 dias com rações contendo fosfato com diferentes relações flúor:fósforo

\begin{tabular}{|c|c|c|c|c|c|}
\hline & \multicolumn{4}{|c|}{ Relação flúor:fósforo } & \multirow[t]{2}{*}{ CV (\%) } \\
\hline & $1: 40$ & $1: 60$ & $1: 80$ & $1: 100$ & \\
\hline \multicolumn{6}{|c|}{ Tíbia (g/kg) } \\
\hline Cálcio & $391,20 a$ & $445,26 a$ & $477,67 a$ & $416,31 a$ & 18,67 \\
\hline Fósforo & $188,12 \mathrm{a}$ & $177,60 a$ & $186,11 \mathrm{a}$ & $191,19 a$ & 12,51 \\
\hline Magnésio & 6,65ab & $5,98 b$ & $7,47 a$ & $7,41 \mathrm{a}$ & 15,11 \\
\hline Flúor & $1,64 a$ & $0,46 \mathrm{~b}$ & $0,37 b$ & $0,21 \mathrm{c}$ & 17,58 \\
\hline \multicolumn{6}{|c|}{ Peito (g/kg) } \\
\hline Cálcio & $5,74 a$ & $6,14 \mathrm{a}$ & $6,15 a$ & $6,07 \mathrm{a}$ & 8,27 \\
\hline Fósforo & $2,65 a$ & $2,49 a$ & $2,12 \mathrm{a}$ & $1,54 \mathrm{a}$ & 45,45 \\
\hline Magnésio & $0,81 \mathrm{a}$ & $0,81 \mathrm{a}$ & $0,77 a$ & $0,85 a$ & 14,40 \\
\hline Flúor & $0,02 \mathrm{a}$ & $0,02 \mathrm{a}$ & $0,02 \mathrm{a}$ & $0,02 \mathrm{a}$ & 11,82 \\
\hline
\end{tabular}

Médias seguidas de mesma letra, dentro de cada variável analisada, não diferem $(P>0.05)$ pelo teste Tukey.

de Veloso et al. (1996) de que os teores de flúor nos ossos foram significativamente influenciados pelas fontes de fósforo, pois foram mais altos quando fornecidas fontes mais ricas em flúor. Isso indica, segundo esses autores, que a deposição óssea de flúor está relacionada à sua concentração na ração e, ainda, que esteja presente nas fontes de fósforo na forma solúvel, absorvível ou disponível para frangos de corte. A concentração de cálcio e fósforo ósseos também não foi afetada quando frangos de corte foram alimentados com rações formuladas com diferentes fontes de fósforo e diferentes concentrações de flúor (Rama Rao \& Reddy, 2003; Hemme et al., 2005).

Na análise dos dados referentes à deposição muscular de cálcio, fósforo, magnésio e flúor, não houve diferença estatística entre os tratamentos, comprovando que a concentração de flúor na dieta não influenciou a deposição muscular desse mineral. Segundo Haman et al. (1936), a baixa retenção de flúor na musculatura das aves pode estar relacionada à eliminação mais eficiente desse elemento. Além disso, de acordo com Borges et al. (1998), a ingestão de $100 \mathrm{~g}$ de tecido muscular provenientes de aves alimentadas com fosfatos naturais não forneceria mais que $0,5 \mathrm{mg}$ de flúor para o homem. Segundo Underwood (1981), seria necessária ingestão diária de 3,0 a 36,0 mg de flúor para que ocorresse o problema da fluorose. Borges et al. (1998), estudando a deposição de flúor de diferentes fontes de fósforo nos tecidos moles de frangos de corte, concluíram que houve maior deposição de flúor nos tecidos da moela, do fígado, do coração e da musculatura da coxa das aves alimentadas com fosfatos naturais, no entanto, esses valores podem ser considerados normais e, provavelmente, sem riscos para a saúde humana. 
A deposição de magnésio foi estatisticamente maior nas aves alimentadas com menores concentrações de flúor, o que contraria observações de Chan et al. (1973) e Merkley (1976), que verificaram maior deposição óssea de magnésio com o aumento do teor de flúor da fonte utilizada. Segundo Underwood (1971), é necessário nível de saturação de 15.000 a $20.000 \mathrm{mg} / \mathrm{kg}$ de flúor nos ossos para que ocorra acúmulo desse elemento nos tecidos.

\section{Conclusões}

A utilização das relações flúor:fósforo 1:40, 1:60, 1:80 e 1:100 na dieta não afeta o desempenho de frangos de corte. A deposição óssea de flúor é proporcional à sua concentração na dieta, no entanto, a elevação dos níveis de flúor da dieta não influencia sua deposição nos músculos e, portanto, não representa riscos à saúde humana.

\section{Literatura Citada}

BORGES, F.M.O.; VELOSO, J.A.F.; BAIÃO, N.C. et al. Deposição de flúor de diferentes fontes de fósforo nos tecidos moles de frangos de corte. Arquivo Brasileiro de Medicina Veterinária e Zootecnia, v.50, p.69-73, 1998.

CAVALHEIRO, A.C.L.; FERREIRA, C.L.B.; TRINDADE, D.S. et al. Avaliação de algumas fontes de fósforo em rações para poedeiras. Revista da Sociedade Brasileira de Zootecnia, v.15, p.269-276, 1986.

CHAN, M.M.; RUCKER, R.B.; ZEMAN, F. et al. Effect of fluorine on bone formation strength in Japanese quail. Journal of Nutrition, v.103, n.10, p.1431-1440, 1973.

DE BRUYNE, K.; VON FELDE, A. Quality feed phosphates - strategies for implementing digestible phosphorus. Feed Magazine, v.5, p.210-215, 2000.

GARDINER, J.W. Nutritional aspects of fluorine toxicosis. Journal of Animal Science, v.51, n.3, p.759-766, 1961.

GARDNER, E.E.; WINCHELL, K.S.; HIRONAKA, R. The influence of dietary sodium fluoride on the utilization and metabolizable energy value of a poultry diet. Poultry Science, v.47, p.12411244, 1968.

GERRY, R.W. Raw rock phosphate in laying rations. Poultry Science, v.28, p.19-23, 1949.

GOMES, P.C. Disponibilidade de fósforo em fosfatos não convencionais para suínos e aves. In: MINI-SIMPÓSIO DO COLÉGIO BRASILEIRO DE NUTRIÇÃO ANIMAL, 6., 1991, Campinas. Anais... Campinas: Colégio Brasileiro de Nutrição Animal, 1991. p.79-96.

GOMES, P.C.; PEREIRA, J.A. Efeitos das fontes, disponibilidade e nível de fósforo na ração de suínos na fase inicial. Revista da Sociedade Brasileira de Zootecnia, v.18, n.3, p.248-259, 1989.
GUINOTTE, F.; NYS, Y.; MONREDON, F. The effects of particle size and origin of calcium carbonate on performance and ossification characteristics in broiler chicks. Poultry Science, v.70, n.9, p.1908-1920, 1991.

HAMAN, K.; PHILLIPS, P.H.; HALPIN, J.G. The distribuition and storage of fluorine in the tissue of the laying hen. Poultry Science, v.15, p.154-157, 1936

HEMME, A.; SPARK, M.; WOLF, P. et al. Effects of different phosphorus sources in the diet on bone composition and stability (breaking strength) in broilers. Journal of Animal Physiology and Animal Nutrition, v.89, p.129-133, 2005.

JUNQUEIRA, O.M. Desempenho produtivo de aves alimentadas com fosfato não convencionais. In: MINI SIMPÓSIO DO COLÉGIO BRASILEIRO DE NUTRIÇÃO, 6., 1991, Campinas. Anais... Campinas: Colégio Brasileiro de Nutrição Animal, 1991. p.121-136.

KARUNAJEEWA, $\mathrm{H}$. The supplemental value of some inorganic sources of phosphorus for broiler chicks. Austriac Journal Agriculture Animal Husbandry, v.15, p.766-772, 1975.

LOURENÇO, A.T.A.; ARIKI, J.; BUTOLO, J.E. et al. Fosfato de Patos de Minas como fonte de fósforo em rações de frangos de corte. Revista da Sociedade Brasileira de Zootecnia, v.15, p.350-355, 1986.

MERKLEY, J.W. Increase bone strength in coop-reared broilers provided fluoridated water. Poultry Science, v.55, p.13131319, 1976.

NATIONAL RESEARCH COUNCIL - NRC. Effects of fluorides in animals. Washington, D.C.: National Academy Press, 1974. 70p.

NATIONAL RESEARCH COUNCIL - NRC. Nutrient requirements of poultry. Washington, D.C.: National Academy Press. 9.rev.ed. 1994.

RAMA RAO, S.V.; REDDY, V.R. Utilization of different phosphorus sources in relation to their fluorine content for broilers and layers. British Poultry Science, v.42, p.376-383, 2001.

RAMA RAO, S.V.; REDDY, V.R. Relative bio-availability and utilization of phosphatic fertilisers as sources of phosphorus in broilers and layers. British Poultry Science, v.44, p.96-103, 2003.

REZENDE, M.J.M.; VELOSO, J.A.F.; TURCHETTI-MAIA, R.M.M. Effect of dietary fluorine from Araxá rock phosphate on the hepatic production of cyclic-adenosine monophosphate in broilers. Arquivo Brasileiro de Medicina Veterinária e Zootecnia, v.51, p.447-484, 1999.

ROGLER, M.; PARKER, H. The fluorine problem in livestock feeding. Nutrition of Revision, v.21, n.4, p.787-804, 1972.

ROSA, I.V. Fósforo, fosfato de rocha e fluorose em bovinos. In SIMPÓSIO DO COLÉGIO BRASILEIRO DE NUTRIÇÃO ANIMAL, 2., 1988, Campinas. Anais... Campinas: Colégio Brasileiro de Nutrição Animal, 1988. p.89-95.

SPIERTO, K. The distribuition and storage of fluorine in the tissue of laying hen. Poultry Science, v.15, n.2, p.154-157, 1969.

VELOSO, J.A.F.; BORGES, F.M.O.; FURTADO, M.A. et al. Fósforo disponível de dez fontes dobre o desempenho de frangos de corte. Arquivos Brasileiros de Medicina Veterinária e Zootecnia, v.48, n.6, p.741-753, 1996.

UNDERWOOD, E.J. The mineral nutrition of livestock. 2.ed Farmhan Royal: 1981. 180p.

UNDERWOOD, E.J. Trace elements in human and animal nutrition. 3.ed. New York: Academic Press, 1971. 543p. 